Article

\title{
Resistive Switching in Non-Stoichiometric Germanosilicate Glass Films Containing Ge Nanoclusters
}

\author{
Vladimir A. Volodin ${ }^{1,2}, *\left(\mathbb{D}\right.$, Pavel Geydt ${ }^{2, *} \mathbb{0}$, Gennadiy N. Kamaev ${ }^{1,2}$, \\ Andrei A. Gismatulin 1,2, Grigory K. Krivyakin 1,2, Igor P. Prosvirin ${ }^{3}$, Ivan A. Azarov 1,2, \\ Zhang Fan ${ }^{2}$ and Michel Vergnat ${ }^{4}$ (D) \\ 1 Rzhanov Institute of Semiconductor Physics SB RAS, Lavrentiev Ave., 13, 630090 Novosibirsk, Russia; \\ kamaev@isp.nsc.ru (G.N.K.); aagismatulin@isp.nsc.ru (A.A.G.); g.krivyakin@nsu.ru (G.K.K.); \\ i.azarov@nsu.ru (I.A.A.) \\ 2 Physical Faculty, Novosibirsk State University, Pirogova Street, 2, 630090 Novosibirsk, Russia; \\ f.chzhan@g.nsu.ru \\ 3 Boreskov Institute of Catalysis SB RAS, Lavrentiev Ave., 5, 630090 Novosibirsk, Russia; \\ prosvirin@catalysis.ru \\ 4 CNRS, IJL, Université de Lorraine, F-54000 Nancy, France; michel.vergnat@univ-lorraine.fr \\ * Correspondence: volodin@isp.nsc.ru (V.A.V.); p.geydt@nsu.ru (P.G.)
}

Received: 10 November 2020; Accepted: 7 December 2020; Published: 10 December 2020

check for updates

\begin{abstract}
Metal-insulator-semiconductor (MIS) structures based on thin $\mathrm{GeO}\left[\mathrm{SiO}_{2}\right]$ and $\mathrm{GeO}[\mathrm{SiO}]$ films on Si substrates were fabricated with indium-tin-oxide as a top electrode. The samples were divided it two series: one was left as deposited, while the second portion of MIS structures was annealed at $500{ }^{\circ} \mathrm{C}$ in argon for $20 \mathrm{~min}$. The structural properties of as-deposited and annealed non-stoichiometric germanosilicate $\left(\mathrm{GeSi}_{\mathrm{x}} \mathrm{O}_{\mathrm{y}}\right)$ films were studied using X-ray photoelectron spectroscopy, electron microscopy, Raman and infrared absorption spectroscopy, spectral ellipsometry, and transmittance and reflectance spectroscopy. It was found that the as-deposited $\mathrm{GeO}[\mathrm{SiO}]$ film contained amorphous Ge clusters. Annealing led to the formation of amorphous Ge nanoclusters in the $\mathrm{GeO}\left[\mathrm{SiO}_{2}\right]$ film and an increase of amorphous $\mathrm{Ge}$ volume in the $\mathrm{GeO}[\mathrm{SiO}]$ film. Switching from a high resistance state (HRS OFF) to a low resistance state (LRS ON) and vice versa was detected in the as-deposited and annealed MIS structures. The endurance studies showed that slight degradation of the memory window occurred, mainly caused by the decrease of the ON state current. Notably, intermediate resistance states were observed in almost all MIS structures, in addition to the HRS and LRS states. This property can be used for the simulation of neuromorphic devices and related applications in data science.
\end{abstract}

Keywords: germanosilicate glass; memristor; Ge nanoclusters; resistance states; thin films

\section{Introduction}

The development of information technologies requires devices for storing and processing huge amounts of information. Therefore, the creation of a universal storage device with a high speed of writing and reading information, along with a long storage time, high information capacity, and low operation power, is highly demanded in the field of nanoelectronics [1]. The capacity of memory matrices continues to grow while the planar integration of memory elements has almost reached its physical limits, which stimulates research of new physical principles and new materials for memory elements. In 1971, Leon Chua theoretically predicted the existence of the fourth element of electronics: a memory resistor, also called a memristor [2]. In 2008, Stanley Williams and his co-authors discovered 
a memristor effect in a thin titanium oxide film, manifesting what "the missing memristor found" [3]. The memristor effect is based on the controlled switching of dielectrics to high and low resistance states (HRS and LRS, respectively). In 2013, Panasonic Semiconductor Solutions launched eight-bit MN101LR series microcontrollers with integrated, resistive random-access memories (ReRAMs) based on $\mathrm{Ta}_{2} \mathrm{O}_{5} / \mathrm{TaO}_{2}$ double layers using 180-nanometer technology [4]. With a giant capacity of information storage in nonvolatile ReRAM, it is assumed that its energy consumption will be low. Presumably, only spintronic-based memory and ferroelectric RAM (FeRAM) can compete with ReRAM in energy consumption.

To date, the memristor effect has been observed in a wide class of different materials: perovskite films [5], organic films [6], fluorides and graphene oxides [7], high-k dielectrics such as $\mathrm{TiO}_{2}, \mathrm{HfO}_{2}$ [8], $\mathrm{ZrO}_{2}, \mathrm{Ta}_{2} \mathrm{O}_{5}$ [9], $\mathrm{Ta}_{2} \mathrm{O}_{5-\mathrm{x}} / \mathrm{TaO}_{2-\mathrm{x}}$ [10], $\mathrm{Nb}_{2} \mathrm{O}_{5}, \mathrm{Al}_{2} \mathrm{O}_{3}$, germanium oxides like $\mathrm{GeO}_{x}$ [11], and silicon nitrides like $\mathrm{SiN}_{\mathbf{x}}$ [12]. It is especially important to develop memristors based on materials that are fully compatible with simple silicon planar technology, such as materials like silicon oxide $\mathrm{SiO}_{x}$ [13-17]. The important advantage of non-stoichiometric germanosilicate glasses $\left(\mathrm{GeSi}_{\mathrm{x}} \mathrm{O}_{\mathrm{y}}\right.$ solid alloys) are that the technology of their deposition is simple, inexpensive, and fully compatible with modern silicon technology [18]. These films are also interesting because they contain charge traps of various types. The nanoscale fluctuations of the potential in these solid alloys are due to the presence of $\mathrm{SiO}_{x}, \mathrm{GeO}_{x}, \mathrm{Si}$, or Ge nano-inclusions. The bandgap values in $\mathrm{SiO}_{2}(8-9 \mathrm{eV})$, $\mathrm{GeO}_{2}(4-5 \mathrm{eV})$, and $\mathrm{Ge}(0.7 \mathrm{eV})$ differ significantly. The nano-inclusions of germanium oxides in silicon oxide are relatively shallow traps. Nano-precipitates with an excess of germanium atoms (or oxygen deficit regions) and Ge nanoclusters are quite deep traps.

Recently, there has been an increasing interest in materials with a low enthalpy of bonds between an atom of the fourth group of the periodic table of elements and an oxygen atom for the formation of memristors. This is because an easier formation of conductive filaments and their easier rupture in such materials are assumed. This softening should reduce the operation power for switching between the states, but it is also expected to reduce retention and endurance. On the one hand, softening can lead to the appearance of regimes of the intermediate resistance states (IRSs) in memristors. These states, supposedly, can be useful for the simulation of neuromorphic devices (e.g., stimulating synaptic plasticity and preliminary spike-enhanced plasticity) [19]. Multilevel resistance states in nanoscale neuromorphic devices with retention time satisfaction can be used as prospective artificial synapses [20].

\section{Experiment}

The samples of the non-stoichiometric germanosilicate glasses (i.e., $\mathrm{GeSi}_{\mathrm{x}} \mathrm{O}_{\mathrm{y}}$ solid alloys) were fabricated with a heating evaporation technique similar to the one previously described in [18]. After simultaneous evaporation of the $\mathrm{GeO}_{2}$ and $\mathrm{SiO}_{2}$ (or $\left.\mathrm{SiO}\right)$ powders in a high vacuum $\left(10^{-8}\right.$ Torr), deposition onto heavily doped $\mathrm{n}^{+}$-type (resistivity $0.005 \mathrm{Ohm} \cdot \mathrm{cm}$ ) and $\mathrm{p}^{+}$-type (resistivity $0.01 \mathrm{Ohm} \cdot \mathrm{cm}$ ) Si (001) substrates heated up to $100^{\circ} \mathrm{C}$ occurred. The standard quartz microbalance method allowed for controlling the deposition rate at the level of $\sim 0.1 \mathrm{~nm} / \mathrm{s}$. Two series of films were prepared by (1) evaporation of $\mathrm{GeO}_{2}$ and $\mathrm{SiO}_{2}$ powdered sources in accordance with the chemical composition, which we will refer to as $\mathrm{GeO}\left[\mathrm{SiO}_{2}\right]$, and (2) evaporation of $\mathrm{GeO}_{2}$ and $\mathrm{SiO}$ powdered sources in accordance with the chemical composition, marked as $\mathrm{GeO}[\mathrm{SiO}]$ film. Note that, according to previous studies $[21,22]$ on the condition of the evaporation of germanium dioxide powder, $\mathrm{GeO}_{x}$ films of a composition very close to germanium monoxide $(\mathrm{x} \sim 1 \div 1.1)$ were deposited on the substrate. Presumably, this was due to the fact that germanium monoxide is a very volatile compound (i.e., it evaporates when an electron beam heats the targeted germanium dioxide powder and condenses on a cold substrate). The accompanying evaporating oxygen did not interact actively with the deposited film and practically did not oxidize germanium monoxide. The silicon substrates were cleaned in deionized water and dried. Thus, the growth of films was carried out on the native silicon oxide layer with a thickness of $2-3 \mathrm{~nm}$. In addition, thick $(\sim 400 \mathrm{~nm})$ reference samples were deposited on n-type 
$(10 \mathrm{Ohm} \cdot \mathrm{cm}) \mathrm{Si}(100)$ silicon and quartz substrates in the same deposition regimes for specific structural and optical studies.

The X-ray photoelectron spectra (XPS) were measured using the SPECS photoelectron spectrometer (Germany) with a PHOIBOS-150-MCD-9 hemispherical analyzer and a FOCUS-500 X-ray monochromator ( $\mathrm{AlK}_{\alpha}$ line, $\left.h v=1486.74 \mathrm{eV}, 200 \mathrm{~W}\right)$. The binding energy scale was previously calibrated by the position of the peaks of the core levels of the $A u 4 f_{7 / 2}(84.00 \mathrm{eV})$ and the $\mathrm{Cu} 2 \mathrm{p}_{3 / 2}$ $(932.67 \mathrm{eV})$. The sample was mounted on double-sided copper conductive tape. For calibration, the C1s line (binding energy is $284.8 \mathrm{eV}$ ) from carbon, contained in hydrocarbons presenting on the surface of the samples, was used [23].

The JEM-2200FS transmission electron microscope (JEOL, Akishima, Japan) was used to investigate the structural properties of the samples. The high-resolution, cross-sectional transmission electron microscopy (HRTEM) mode was used, while the acceleration voltage was $200 \mathrm{kV}$. The Leica EM TXP target preparation device (Leica Microsystems, Mannheim, Germany) was used to prepare the cross-sectional samples by two-step mechanical polishing, followed by ion grinding.

It is known that analysis of vibrational spectroscopy data provides information about chemical bonds. The presence of nonpolar Ge-Ge bonds in the films was verified from analysis of the Raman spectroscopy data. Raman spectra were recorded at room temperature in the backscattering geometry by using an $\mathrm{Ar}^{+}$laser for excitation, whose wavelength was $514.5 \mathrm{~nm}$, and the polarization of the laser irradiation was linear. A T64000 (Horiba Jobin Yvon) Raman spectrometer was used. The polarization of the scattered light was not analyzed. A liquid nitrogen-cooled, silicon-based charge-coupled device (CCD) matrix was used as the spectrometer's photodetector, allowing a spectral resolution no worse than $2 \mathrm{~cm}^{-1}$. The BX41 optical microscope accessory (Olympus, Tokyo, Japan) was used for the micro-scale recording of the Raman spectral data. To avoid local heating of the films by the laser beam, the sample was placed slightly further from the focus. The laser beam power on the sample was $\sim 1 \mathrm{~mW}$, while the spot diameter was $\sim 20 \mu \mathrm{m}$. The polar $\mathrm{Si}-\mathrm{O}$ and $\mathrm{Ge}-\mathrm{O}$ bonds were studied using Fourier-transform infrared (FTIR) absorption spectroscopy. An FT-801 spectrometer (SIMEX analytical equipment, Novosibirsk, Russia) with a spectral resolution of $4 \mathrm{~cm}^{-1}$ was used. As was mentioned earlier, for the FTIR analysis, the thicker $(400 \mathrm{~nm})$ reference films were deposited onto an n-type (resistivity $10 \mathrm{Ohm} \cdot \mathrm{cm}$ ) $\mathrm{Si}(001)$ substrate in the same growth condition.

The optical properties of the non-stoichiometric germanosilicate films in the visible region near the IR and ultraviolet (UV) regions were studied using spectral ellipsometry. An ELLIPS-1891-SAG (Institute of Semiconductor Physics, Novosibirsk, Russia) spectral ellipsometer was used for the ellipsometric analysis of the thin films on nontransparent silicon substrates [24]. The spectral dependencies of the ellipsometric angles $\Psi(\lambda)$ and $\Delta(\lambda)$ were measured in the range of 250-1100 nm. The spectral resolution of the device was about $2 \mathrm{~nm}$, and the angle of light incidence was $70^{\circ}$. The four-zone measurement technique was used, and averaging over all four zones was performed. The SF-56 spectrophotometer (LOMO-Spectr, Saint Petersburg, Russia) was applied for the study of the transmission and reflection of light. The spectral resolution was better than $6 \mathrm{~nm}$ for the measurement range of 190-1100 nm. To record the reflection spectra, a PS-9 module (LOMO-Spectr, Saint Petersburg, Russia) was utilized. The angle of incidence was $9^{\circ}$ with respect to the normal. The recorded spectra were normalized to the reference spectrum obtained for $\mathrm{Si}$, with a natural oxide thickness of $3 \mathrm{~nm}$ like in previous works [25,26].

Square indium tin oxide (ITO) contacts $(0.7 \mathrm{~mm} \times 0.7 \mathrm{~mm})$ with a thickness of $200 \mathrm{~nm}$ were deposited using magnetron sputtering. The layer resistance was $40 \mathrm{Ohm} / \mathrm{r}$, and the contact area was $0.5 \mathrm{~mm}^{2}$. The metal-insulator-semiconductor (MIS) samples were divided into two series: the first portion of structures was left without annealing (as-deposited MIS), while the second series was further annealed at $500{ }^{\circ} \mathrm{C}$ for $20 \mathrm{~min}$. The current-voltage (I-V) characteristics of the MIS structures were measured using a B2902A parameter analyzer (Agilent, Santa Clara, CA, USA) with a micro-probe station. The I-V measurements and positive and negative voltages were applied to the top ITO electrodes, while the back Si substrate electrodes had always been grounded. The equipment was 
automated, which made it possible to measure the currents in ON and OFF states after the $\mathrm{ON}$ and OFF pulses, respectively, in order to investigate the endurance of the memristors.

\section{Results and Discussion}

\subsection{Structural Studies}

Figure 1 displays the XPS of the as-deposited thin $\mathrm{GeO}\left[\mathrm{SiO}_{2}\right]$ and $\mathrm{GeO}[\mathrm{SiO}]$ films. In addition to the survey XPS (Figure 1a), narrow spectral regions of the valence band (Figure 1b), Ge3d (Figure 1c), Si2p (Figure 1d), and O1s (Figure 1e) were measured. Survey spectra and individual spectral regions were obtained using the fixed analyzer pass energy of $50 \mathrm{eV}$ and $20 \mathrm{eV}$, respectively. The survey spectra (Figure 1a) exhibited intense photoelectron peaks characteristic of germanium, silicon, oxygen, and carbon. No additional peaks belonging to other elements were found. The relative content of elements near the surface of the samples and the ratio of atomic concentrations were determined using the integrated intensities of photoelectron lines corrected for the corresponding atomic sensitivity factors, based on the Scofield's calculations of the cross-sections [27]: 1.42 for Ge3d, 0.817 for Si2p, 1.0 for $\mathrm{C} 1 \mathrm{~s}$, and 2.93 for O1s. As such, for the as-deposited thin $\mathrm{GeO}\left[\mathrm{SiO}_{2}\right]$ sample, the $\mathrm{O} / \mathrm{Si}$ ratio was 4.89 , and the $\mathrm{Ge} / \mathrm{Si}$ ratio was 1.43 . For the $\mathrm{GeO}[\mathrm{SiO}]$ sample, the $\mathrm{O} / \mathrm{Si}$ ratio was 3.17 , and the $\mathrm{Ge} / \mathrm{Si}$ ratio was 1.04. The near-surface composition of the samples is presented in Table 1. It should be noted that the oxygen content in the near-surface region of the samples was found to be larger than assumed, according to the growth conditions $\left(60 \%\right.$ for $\mathrm{GeO}\left[\mathrm{SiO}_{2}\right]$ and $50 \%$ for $\left.\mathrm{GeO}[\mathrm{SiO}]\right)$. This could have resulted from the oxidation of the near-surface region of the samples during their storage in the air atmosphere.

Table 1. The near-surface composition of the studied samples in atomic percents.

\begin{tabular}{cccc}
\hline Sample & Ge, at.\% & Si, at.\% & O, at.\% \\
\hline $\mathrm{GeO}\left[\mathrm{SiO}_{2}\right]$ & 19.5 & 13.7 & 66.8 \\
$\mathrm{GeO}[\mathrm{SiO}]$ & 20.0 & 19.2 & 60.8 \\
\hline
\end{tabular}

Figure 1c shows the spectra of the Ge3d region of the as-deposited samples. The binding energy of the most intense peak in both spectra was $32.8 \pm 0.1 \mathrm{eV}$. This value is characteristic of germanium bound to four oxygen atoms, for example, in $\mathrm{GeO}_{2}[23,28]$. The low-intensity peak at $\sim 31.2 \pm 0.2 \mathrm{eV}$ can be attributed to germanium in a non-stoichiometric oxide, $\mathrm{GeO}_{x}$ [28]. In addition to the two indicated peaks, the shoulder with a lower binding energy at $29.5 \pm 0.1 \mathrm{eV}$ was observed in the spectrum of the $\mathrm{GeO}[\mathrm{SiO}]$ sample, which can be attributed to the germanium clusters (Ge-Ge bonds) [29]. Figure 1c also shows the result of the Ge3d spectra's deconvolution into separate spectral components, carried out

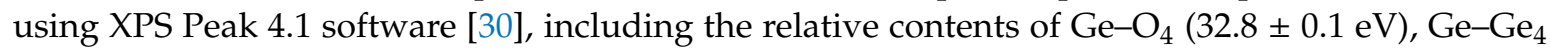
$(29.5 \pm 0.1 \mathrm{eV})$, and $\mathrm{Ge}-\mathrm{O}_{\mathrm{x}} \mathrm{Ge}_{(4-\mathrm{x})}(\mathrm{x}=1,2,3,31.2 \pm 0.2 \mathrm{eV})$ tetrahedrons. The $\mathrm{Ge}-\mathrm{O}_{\mathrm{x}} \mathrm{Ge}_{(4-\mathrm{x})}(\mathrm{x}=1$, $2,3)$ tetrahedrons actually should have appeared as three separate peaks, but they were not resolved in the spectra.

Figure $1 \mathrm{~d}$,e shows the spectra of the $\mathrm{Si} 2 \mathrm{p}$ and $\mathrm{O} 1$ s regions of the $\mathrm{GeO}\left[\mathrm{SiO}_{2}\right]$ and $\mathrm{GeO}[\mathrm{SiO}]$ samples, respectively. It was suggested that they were a superposition of the $\mathrm{SiO}+\mathrm{SiO}_{2}$ peaks in the $\mathrm{Si2p}$ spectra, and oxygen peaks arose from the germanium and silicon oxides in the O1s spectra. Detailed analysis of Figure 1a-e revealed that there were no $\mathrm{Si}-\mathrm{Si}$ bonds (at least not in detectable quantities) in both samples, while $\mathrm{Ge}-\mathrm{Ge}$ bonds were detected in the $\mathrm{GeO}[\mathrm{SiO}]$ sample. This conclusion was confirmed by the analysis of the valence band spectra (Figure 1b), where the tails in the density of states propagating almost to zero binding energy could be observed, which was due to the $\mathrm{GeO}_{\mathrm{x}}$ inclusions in the films. The peak $\sim 3 \mathrm{eV}$ in the spectrum of $\mathrm{GeO}[\mathrm{SiO}]$ was also due to $\mathrm{Ge}-\mathrm{Ge}$ bonds.

The cross-sectional HRTEM images of the as-deposited samples are shown in Figure 2 (2a for $\left.\mathrm{GeO}\left[\mathrm{SiO}_{2}\right]\right)$ and $2 \mathrm{~b}$ for $(\mathrm{GeO}[\mathrm{SiO}])$. Darker spots correspond to the Ge reach areas. It can be seen that only a few dark spots existed in the $\left.\mathrm{GeO}_{3} \mathrm{SiO}_{2}\right]$ sample. They presumably correspond to the $\mathrm{GeO}_{x}$ areas. 
Remarkably, many dark spots can be seen in the $\mathrm{GeO}[\mathrm{SiO}]$ sample. They presumably correspond to the amorphous Ge clusters [31] (a-Ge), with an average size of about $3 \mathrm{~nm}$. The surfaces of both samples had very low values of surface roughness in the scale of $1 \mathrm{~nm}$, which was controlled by an atomic force microscopy study of their surface topographies (See Figures S1 and S2 in Supplementary Materials).
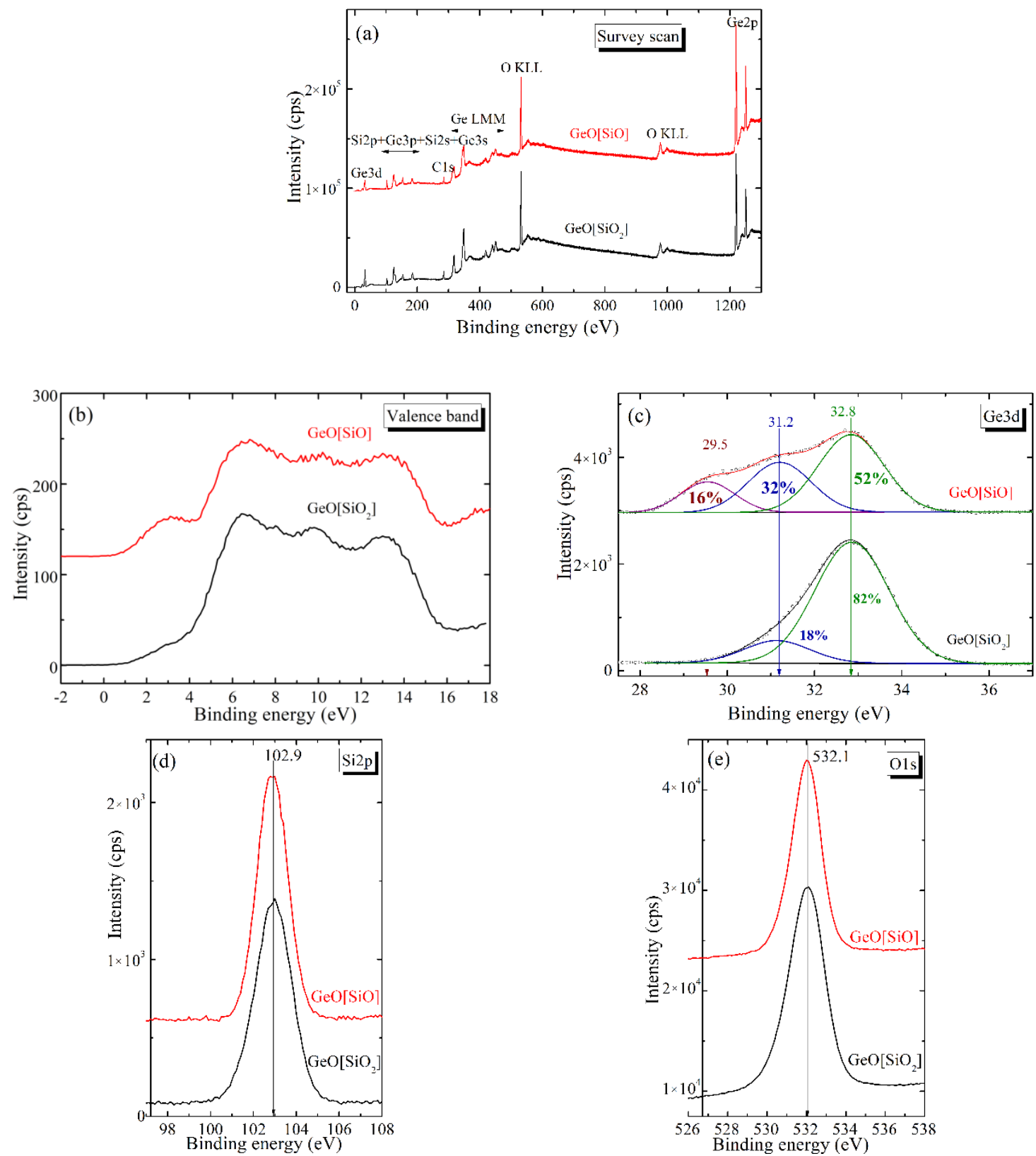

Figure 1. X-ray photoelectron spectra (XPS) data of the as-deposited thin $\mathrm{GeO}\left[\mathrm{SiO}_{2}\right]$ and $\mathrm{GeO}[\mathrm{SiO}]$ films. (a) Survey spectra; (b) valence band region; (c) Ge3d region; (d) Si2p region; and (e) O1s region.

Figure 3a displays the Raman spectra of both the as-deposited and annealed $\mathrm{GeO}\left[\mathrm{SiO}_{2}\right]$ and $\mathrm{GeO}[\mathrm{SiO}]$ thin films, together with a reference spectrum measured from a virgin $\mathrm{Si}(001)$ substrate. For the as-deposited films as well as for the substrate, one could identify a peak at $\sim 305 \mathrm{~cm}^{-1}$, which was due to two-phonon scattering on transversal acoustic phonons (2TA) [32]. This was because these thin films were semi-transparent. Thus, both the one-phonon scattering peak $\left(520 \mathrm{~cm}^{-1}\right)$ and two-phonon scattering peculiarity (2TA, $\sim 305 \mathrm{~cm}^{-1}$ ) could be observed for the Si substrate. It should be noted that some asymmetry of the $520 \mathrm{~cm}^{-1}$ peak was due to Fano interference (interference of phonon and light hole-heavy hole scattering) in the $\mathrm{p}^{+}$-type heavily doped silicon [33]. In the spectrum of the 
as-deposited $\mathrm{GeO}[\mathrm{SiO}]$ film, one could observe a broad peak centered at about $275 \mathrm{~cm}^{-1}$, which could be attributed to amorphous Ge [34]. One could see the growth of the intensity of this peak in the $\mathrm{GeO}[\mathrm{SiO}]$ film and the appearance of this peak in the $\mathrm{GeO}\left[\mathrm{SiO}_{2}\right]$ film after annealing. Therefore, annealing led to an increase of the volume of amorphous $\mathrm{Ge}$ nanoclusters in the $\mathrm{GeO}[\mathrm{SiO}]$ film and to the formation of amorphous $\mathrm{Ge}$ nanoclusters in the $\mathrm{GeO}\left[\mathrm{SiO}_{2}\right]$ film.

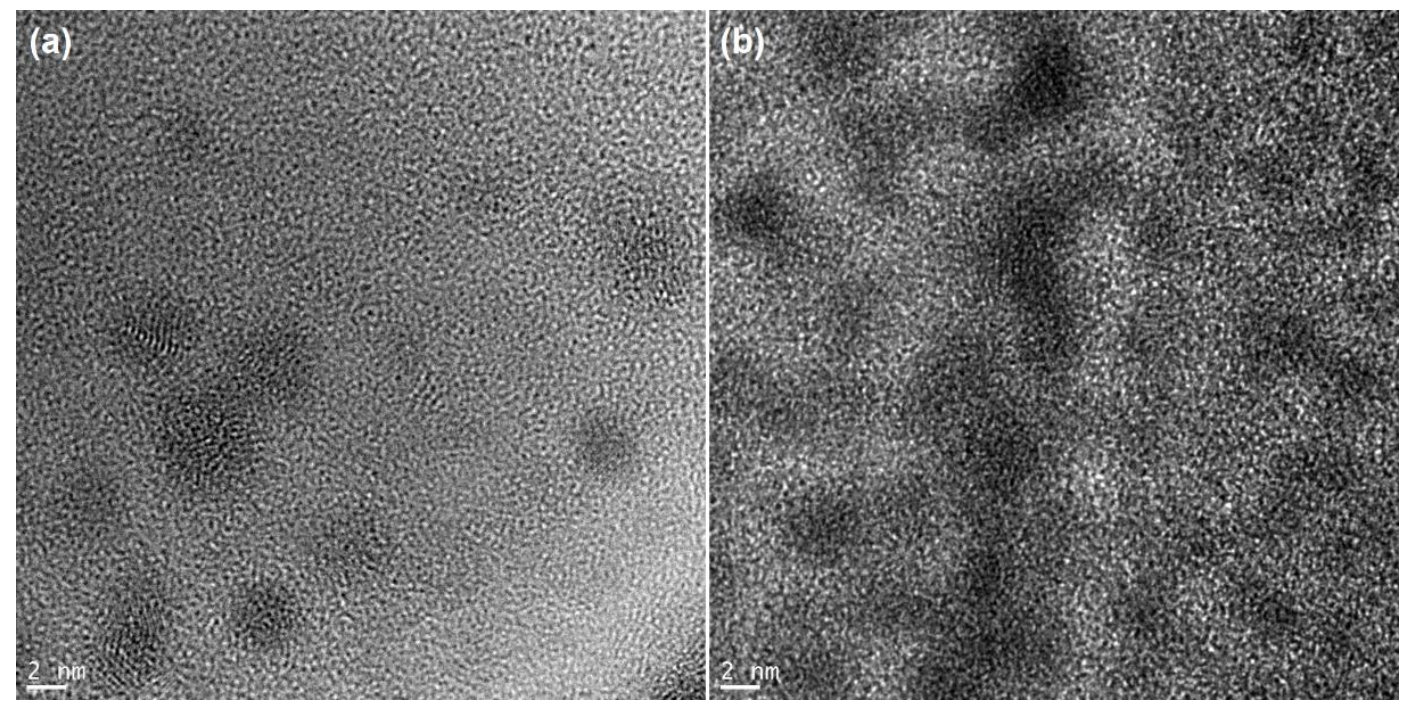

Figure 2. High-resolution transmission electron microscopy (HRTEM) cross-sectional image of the as-deposited thin films, (a) $\mathrm{GeO}\left[\mathrm{SiO}_{2}\right]$ and (b) $\mathrm{GeO}[\mathrm{SiO}]$.
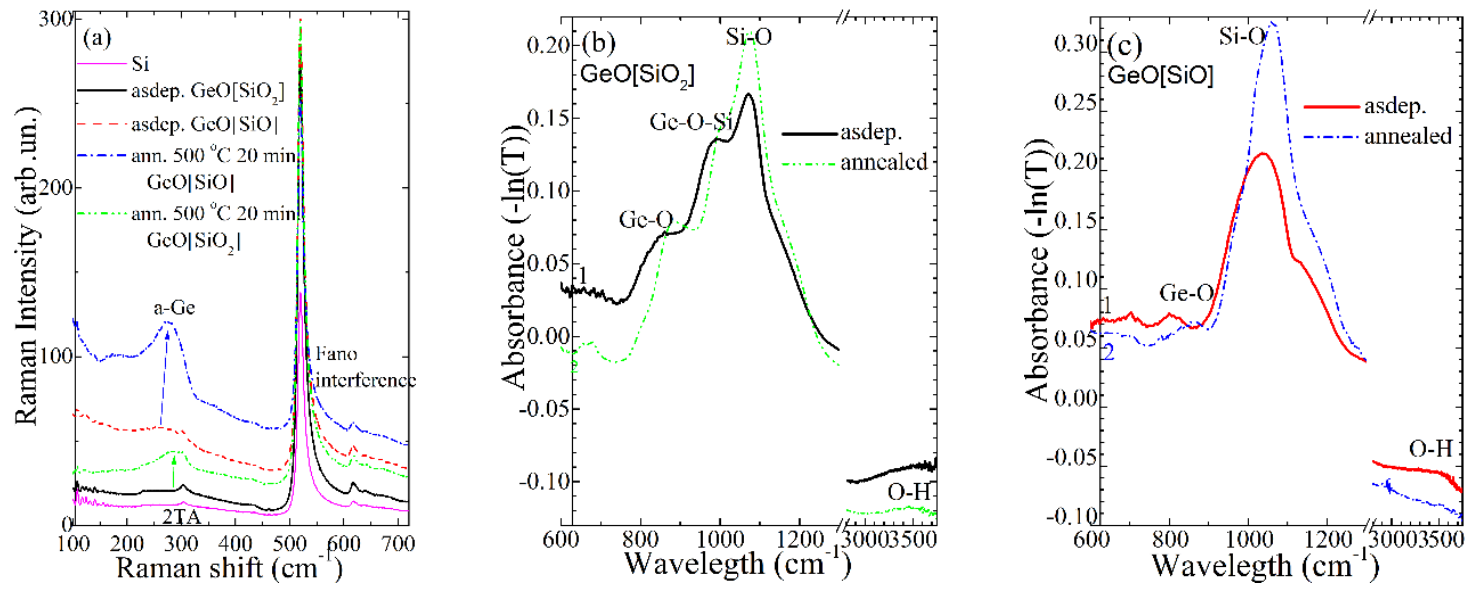

Figure 3. (a) Raman spectra of the $\mathrm{GeO}\left[\mathrm{SiO}_{2}\right]$ and $\mathrm{GeO}[\mathrm{SiO}]$ thin films, measured before and after annealing at $500{ }^{\circ} \mathrm{C}$ for $20 \mathrm{~min}$. A Raman spectrum from a virgin $\mathrm{Si}$ (001) substrate is also shown. (b) Fourier-transform infrared spectroscopy (FTIR) absorption spectra of the thick $\mathrm{GeO}\left[\mathrm{SiO}_{2}\right]$ film (reference sample grown on a substrate not heavily doped with $\mathrm{Si}$ ), measured before and after annealing. (c) FTIR absorption spectra of the thick $\mathrm{GeO}[\mathrm{SiO}]$ film (reference sample grown on a substrate not heavily doped with $\mathrm{Si}$ ), measured before and after annealing.

As it was assumed earlier [18,31,35], the a-Ge clusters appeared due to the following solid-state chemical reaction:

$$
\mathrm{GeO}+\mathrm{SiO} \rightarrow \mathrm{Ge}+\mathrm{SiO}_{2}
$$

After annealing, the intensity of the a-Ge related peak increased in the GeO[SiO] film, which suggests that not all germanium monoxide had deoxidized during deposition, but part of it remained in the form of $\mathrm{GeO}_{\mathrm{x}}$ suboxides. It is known that $\mathrm{GeO}_{\mathrm{x}}$ is unstable and decomposes into germanium and germanium dioxide under annealing with temperatures higher than $300{ }^{\circ} \mathrm{C}[21,36]$. 
Therefore, both annealed films consisted of a germanosilicate suboxide, which contained amorphous germanium (a-Ge) nanoclusters and possibly also a high concentration of oxygen vacancies.

It is known that the analysis of $\mathrm{Si}-\mathrm{O}$ and $\mathrm{Ge}-\mathrm{O}$ polar bond vibrations can provide information about the stoichiometry of $\mathrm{SiO}_{x}$ and $\mathrm{GeO}_{x}$ suboxides. Figure 3b,c shows the FTIR absorption spectra of the as-deposited and annealed thick $\mathrm{GeO}\left[\mathrm{SiO}_{2}\right]$ and $\mathrm{GeO}[\mathrm{SiO}]$ films (these samples were grown on a substrate not heavily doped with $\mathrm{Si}$ ). The virgin n-type $\mathrm{Si}$ substrate with an electrical resistivity of $10 \mathrm{Ohm} \cdot \mathrm{cm}$ was used as a reference when measuring the FTIR absorbance spectra. The spectra were dominated by a major line of approximately $1035-1075 \mathrm{~cm}^{-1}$, that was attributed to the $\mathrm{Si}-\mathrm{O}-\mathrm{Si}$ stretch mode in the $\mathrm{SiO}_{\mathrm{x}}$ films [37,38]. Pai et al. [38] established that the position of this peak (in inverse centimeters) in $\mathrm{SiO}_{\mathrm{x}}$ films almost linearly depends on the stoichiometric parameter $\mathrm{x}$, approximately expressed as

$$
v(\text { Si-O-Si stretching mode })=925+75 x
$$

The position of the $\mathrm{Si}-\mathrm{O}-\mathrm{Si}$ stretching mode peak in the as-deposited $\mathrm{GeO}[\mathrm{SiO}]$ film (red curve, Figure 3c) was $1037 \mathrm{~cm}^{-1}$. Therefore, according to Equation (2), the stoichiometric parameter $\mathrm{x}$ in the as-deposited $\mathrm{GeO}[\mathrm{SiO}]$ film was equal to 1.5 . The position of the $\mathrm{Si}-\mathrm{O}-\mathrm{Si}$ stretching mode peak in the annealed $\mathrm{GeO}\left[\mathrm{SiO}\right.$ ] film (blue curve, Figure 3c) was $1063 \mathrm{~cm}^{-1}$, so the stoichiometric parameter $\mathrm{x}$ in this case was equal to 1.85. Earlier it was supposed [39] that during deposition, not all germanium monoxide participates in a chemical redox such as Reaction (1), and by using the stoichiometric parameter $\mathrm{x}$ in the $\mathrm{SiO}_{\mathrm{x}}$ part of germanosilicate solid alloys, one can determine the share of Ge clusters:

$$
\mathrm{GeO}+\mathrm{SiO} \rightarrow \mathrm{z} \cdot \mathrm{Ge}+(1-\mathrm{z}) \cdot \mathrm{GeO}+\mathrm{SiO}(1+\mathrm{z})
$$

Since the parameter $\mathrm{z}$ was equal to 0.5 in the as-deposited $\mathrm{GeO}[\mathrm{SiO}]$ film, then about half of the germanium monoxide had been deoxidized in the chemical redox, shown in Reaction (1), during its deposition. In the annealed $\mathrm{GeO}[\mathrm{SiO}]$ film, the parameter $\mathrm{z}$ was equal to 0.85 , so about $85 \%$ of the germanium monoxide had been deoxidized in the chemical redox, show in Reaction (3), under deposition and subsequent annealing. As for the as-deposited and annealed $\mathrm{GeO}\left[\mathrm{SiO}_{2}\right]$ films (black and green curve, Figure 3b), the positions of the Si-O-Si stretching mode peak were 1070 and $1075 \mathrm{~cm}^{-1}$, respectively. This suggests that the $\mathrm{SiO}_{\mathrm{x}}$ inclusions in the germanosilicate solid alloy were close to stoichiometric silicon dioxide.

Other peaks visible in the $\mathrm{GeO}\left[\mathrm{SiO}_{2}\right]$ films with a position of $\sim 990 \mathrm{~cm}^{-1}$ (as-deposited film, black curve, Figure $3 b$ ) and $\sim 1000 \mathrm{~cm}^{-1}$ (annealed film, green curve, Figure $3 \mathrm{~b}$ ) were due to the absorption of Ge-O-Si vibrations in the germanosilicate glass $[31,39,40]$. In addition to the $\mathrm{Si}-\mathrm{O}$ and $\mathrm{Si}-\mathrm{O}-\mathrm{Ge}$ peaks, peaks associated with the stretching vibrations of the $\mathrm{Ge}-\mathrm{O}$ bonds in all films [41,42] were seen. Like non-stoichiometric silicon oxide, the position of this peak (in inverse centimeters) in the GeOx films almost linearly depended on the stoichiometric parameter x [42], as

$$
v(\mathrm{Ge}-\mathrm{O} \text { stretching mode })=743+72.4 \mathrm{x}
$$

From the analysis of the Ge-O stretching mode position according to Equation (4), we can conclude that the stoichiometric parameter $\mathrm{x}$ in the GeOx inclusions in the germanosilicate solid alloy was higher than 1.5. An important point is that, for both as-deposited films, one can observe a peak at about $3300 \mathrm{~cm}^{-1}$ due to the presence of $\mathrm{O}-\mathrm{H}$ bonds in those films. The water could be either adsorbed on the surface of the films or contained in the voids of the as-deposited films. In the annealed films, the peaks related to water were much less intense. Thus, the annealing dried the films and presumably removed the voids by a densification process.

It is known that the density of electronic states determines the optical properties of materials; in particular, the mobility gap in dielectrics correlates with the optical gap in them [43]. Therefore, it is important to study the spectral dependence of the optical constants of dielectrics. For this, we used the methods of spectral ellipsometry and transmission and reflection spectroscopy, the results of which 
are presented in Figure 4. Figure 4a,b shows the spectral dependencies of the complex refractive index, with its real part $\mathrm{n}$ and the extinction coefficient (its imaginary part $\mathrm{k}$ ) for the as-deposited thin $\mathrm{GeO}\left[\mathrm{SiO}_{2}\right]$ and $\mathrm{GeO}[\mathrm{SiO}]$ films, respectively. These data were obtained using ellipsometry angles $\Psi(\lambda)$ and $\Delta(\lambda)$ followed by determining the thickness and optical constants of the films from the model, considering one film on the substrate. The thickness of the $\mathrm{GeO}\left[\mathrm{SiO}_{2}\right]$ film was determined to be $85 \mathrm{~nm}$, and the thickness of the $\mathrm{GeO}[\mathrm{SiO}]$ films was $64 \mathrm{~nm}$. One can see that almost no absorption was registered in the $\mathrm{GeO}\left[\mathrm{SiO}_{2}\right]$ film, which was related to the fact that the sensitivity of the method was insufficient to determine weak absorption. In the $\mathrm{GeO}[\mathrm{SiO}]$ film, absorption was observed in the entire spectral range, with growth in the short wavelength edge. The refractive index of the GeO[SiO] film was larger than that of the $\mathrm{GeO}\left[\mathrm{SiO}_{2}\right]$ film, due to the presence of a-Ge clusters in the first case. For estimation of the volume ratio of the Ge clusters in the solid alloy films, an effective medium approximation was used in the Bruggeman approach [44,45]. According to this approach, the volume ratio of a-Ge in the as-deposited $\mathrm{GeO}\left[\mathrm{SiO}_{2}\right]$ film was less than $1 \%$, and the volume ratio of a-Ge in the as-deposited $\mathrm{GeO}[\mathrm{SiO}]$ film was about $10 \%$. For the annealed films (ellipsometry data are not shown here), these ratios were $5 \%$ and $17.5 \%$ for the $\mathrm{GeO}\left[\mathrm{SiO}_{2}\right]$ and $\mathrm{GeO}[\mathrm{SiO}]$ films, respectively. These findings correlate with the Raman spectroscopy data (intensity of the broad $275 \mathrm{~cm}^{-1}$ peak) in Figure 3a.
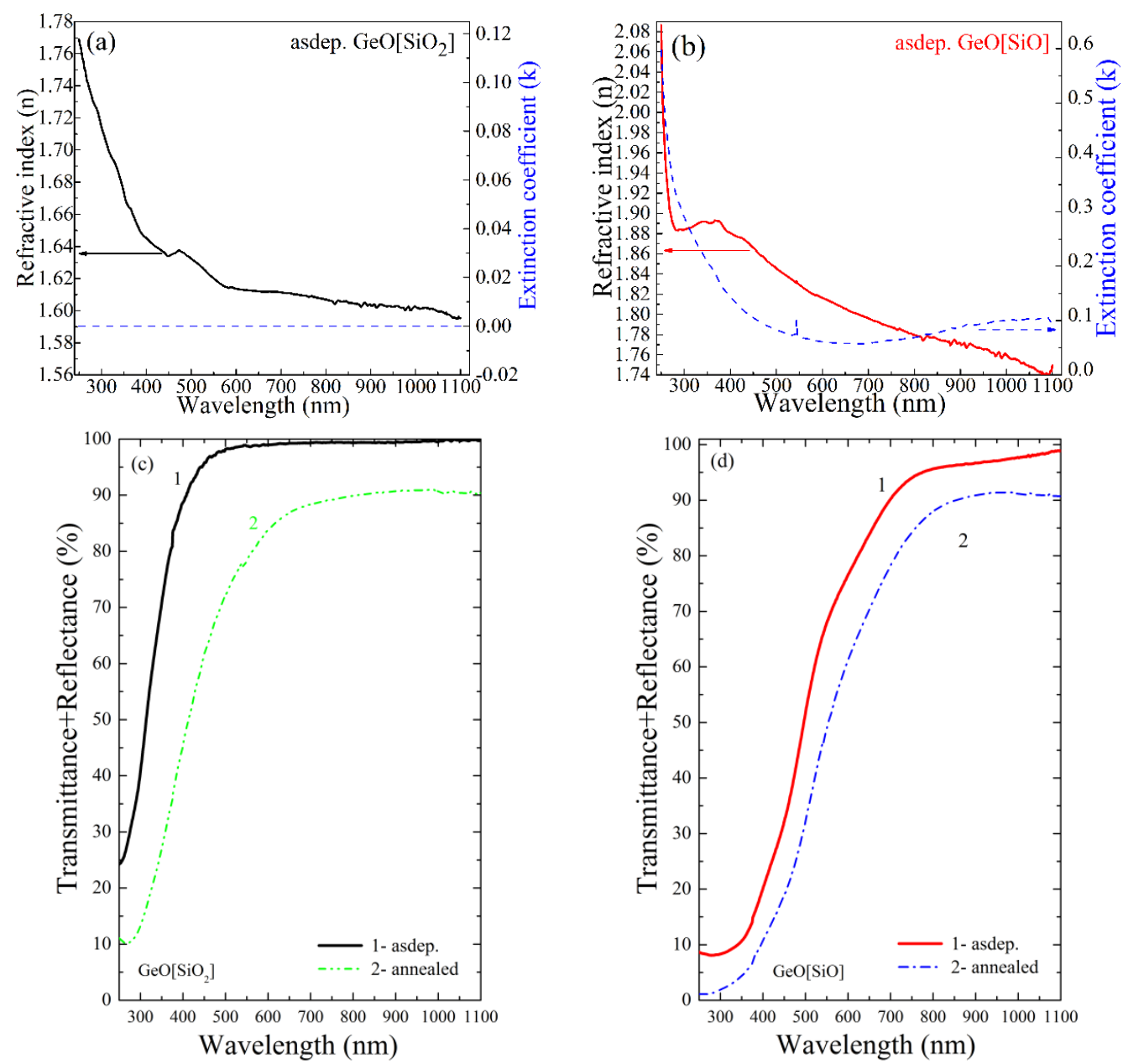

Figure 4. (a,b) Refractive index (its real part $n$ ) and extinction coefficient (imaginary part of refractive index k) of the as-deposited thick $\mathrm{GeO}\left[\mathrm{SiO}_{2}\right]$ and $\mathrm{GeO}[\mathrm{SiO}]$ films, respectively. (c,d) The sum of the transmission and reflection spectra of the as-deposited and annealed thick $\mathrm{GeO}\left[\mathrm{SiO}_{2}\right]$ and $\mathrm{GeO}[\mathrm{SiO}]$ films on quartz substrate, respectively. Separate transmission and reflectance spectra are shown in Figure S3 in Supplementary Materials. 
It should be noted that it was not possible to apply a simple one-film-on-the-substrate model for the analysis of the spectral ellipsometry data of the annealed films. This was because annealing had led to the inhomogeneity of the non-stoichiometric germanosilicate films due to diffusion of the germanium atoms in the Si substrate [46].

The transmission and reflection spectroscopy data (shown in Figure 4c,d) confirmed the spectral ellipsometry results. Recall that the special reference samples on a quartz substrate in the same growth conditions were grown to measure absorbance. To avoid the features associated with interference, the sum of the transmittance and reflectance spectra are compared in Figure 4. One can see almost no absorption in the as-deposited $\mathrm{GeO}\left[\mathrm{SiO}_{2}\right]$ film in the visible and IR ranges (Figure 4c, black curve). The annealing led to the formation of a-Ge clusters in this film and, consequently, to the appearance of absorbance in the visible and IR ranges (Figure 4c, green curve). Since the as-deposited GeO[SiO] film had already contained a-Ge clusters, there was a clear absorbance in this film in the visible and IR ranges (the blue curve in Figure $4 \mathrm{~b}$ and the red curve in Figure $4 \mathrm{~d}$ ). The annealing led to an increasing amorphous Ge volume in this film and, consequently, increased absorbance in the visible and IR ranges (Figure 4d, blue curve).

Therefore, all structural and optical methods confirmed the following statements. The as-deposited $\mathrm{GeO}[\mathrm{SiO}]$ film contained a-Ge nanoclusters, while no such clusters were found in the as-deposited $\mathrm{GeO}\left[\mathrm{SiO}_{2}\right]$ film. Annealing led to an increase in the volume of a-Ge nanoclusters in the $\mathrm{GeO}[\mathrm{SiO}]$ film and to the formation of a-Ge nanoclusters in the $\mathrm{GeO}\left[\mathrm{SiO}_{2}\right]$ film. All films contained $\mathrm{Si}-\mathrm{O}$ and Ge-O bonds.

\subsection{Studies of Resistivity Switching and Endurance}

The schematic image of the MIS structures, energy band diagram, and the scheme of the endurance measurements are shown in Figure 5a-c, respectively. According to our previous studies [47], nanoscale fluctuations of electric potential in sub-oxides can play a considerable role in their electron transport. One of the significant advantages of germanosilicate solid alloys is that they offer the possibility to utilize these nanoscale fluctuations of the potential (i.e., parameters of the energy bands). The bandgap values in $\mathrm{SiO}_{2}$ and $\mathrm{GeO}_{2}$ differ significantly, being $\sim 9 \mathrm{eV}$ and $\sim 5 \mathrm{eV}$, respectively. This difference allows modulation of the parameters of the traps consisting of germanium oxide inclusions in silicon oxide. Other possibilities to establish the nanoscale fluctuations of electric potential are based on the presence of suboxide areas, such as $\mathrm{SiO}_{x}$ and $\mathrm{GeO}_{\mathrm{x}}$, or on the formation of local areas with excess germanium atoms (which can possibly act as traps for both electrons and holes), as well as $\mathrm{a}-\mathrm{Ge}$ nanoclusters. The valence band offset between crystalline $\mathrm{Si}$ and $\mathrm{Ge}$ is approximately $-0.5 \mathrm{eV}$, while the conduction band offset is only about $0.1 \mathrm{eV}$ (as shown in Figure 5b). Since the band offset for Ge is mainly in the valence band, a-Ge nanoclusters act as deep traps for holes rather than for electrons. It is important to note that the quantum size effect leads to a broadening of the bandgap in germanium nanoclusters (Figure 5b), so the larger the a-Ge nanocluster, the deeper the trap for electrons and holes. The band offsets for $\mathrm{Si} / \mathrm{GeO}_{2}$ heterojunctions are known [48]. Thus, yielding barriers for electrons and holes in such a system are about $1.2 \mathrm{eV}$ and $3.3 \mathrm{eV}$, respectively. The corresponding barriers for $\mathrm{Si} / \mathrm{SiO}_{2}$ heterojunctions are also shown in Figure 5b. Unfortunately, the band offsets for $\mathrm{Si} / \mathrm{GeO}$ heterojunctions are unknown.

The typical I-V characteristics of MIS structures grown on a $\mathrm{p}^{+}$-type Si substrate are shown in Figure 6a-d. Switching from an HRS to an LRS (set) was seen at a positive voltage, and reverse switching from an LRS to an HRS (reset) was seen at a negative voltage. The set and reset voltages varied from +2 to $+3.5 \mathrm{~V}$ and from -2.5 to $-3 \mathrm{~V}$ for both as-deposited films (Figure $6 \mathrm{a}, \mathrm{c}$ ). It is worth noting that the current limitation was set during I-V measurements. Therefore, when the structures were switched to an LRS, the current value jumped, and a sharp decrease in the applied voltage was observed (Figure 6b). Insignificant fluctuations of the set and reset voltages of the films could be seen in the studied switching cycles. These results are similar to data obtained earlier using similar as-deposited MIS structures [18]. The ratio of currents in the ON and OFF states (the so-called memory 
window) was rather low (about two to three orders of magnitude), but it should be noted that we carried out the measurements in an air atmosphere. In some cases, for the $\mathrm{SiO}_{\mathrm{x}}$-based memristor (with $\mathrm{Si}$ nanocrystals in $\mathrm{SiO}_{x}$ film), the films did not show any switching effects when $\mathrm{I}-\mathrm{V}$ measurements were carried out in an air atmosphere, while the high ON/OFF ratio was obtained only in a vacuum [15]. It is remarkable that no need to carry out the special forming procedure existed for our structures. This is a noteworthy benefit of our structures, in contrast with the structures reported previously by other authors (e.g., the memristors based on $\mathrm{SiO}_{x}$ with $\mathrm{Si}$ nanocrystal films [15], or in the case of $\mathrm{SiO}_{\mathrm{x}}$ layers deposited by magnetron sputtering [49]). Our MIS structures on the $\mathrm{p}^{+}$-type $\mathrm{Si}$ substrates were forming-free. As one can see from Figure $6 \mathrm{~b}, \mathrm{~d}$, a considerably stable memristor effect was observed in both annealed films. However, in the case of the annealed GeO[SiO]-based MIS structure, a preliminary forming procedure with an applied voltage up to $5 \mathrm{~V}$ was required.

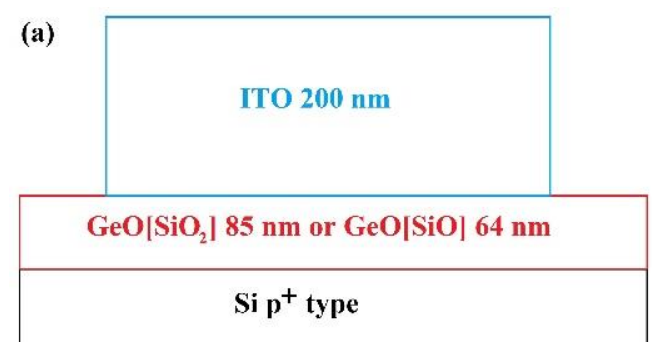

(b)

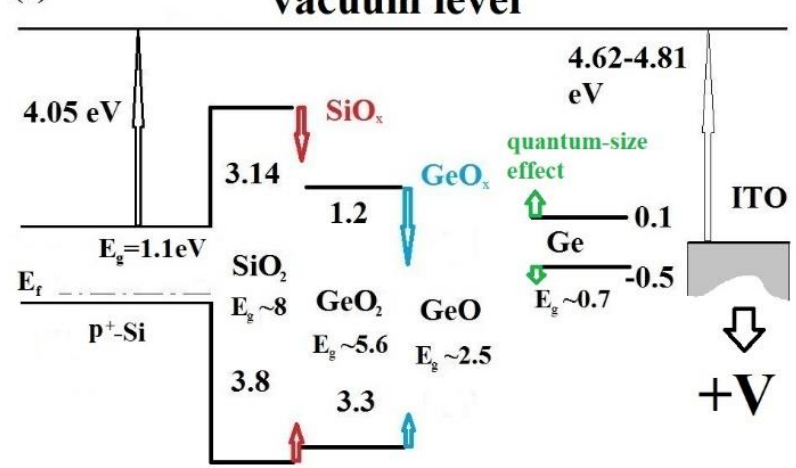

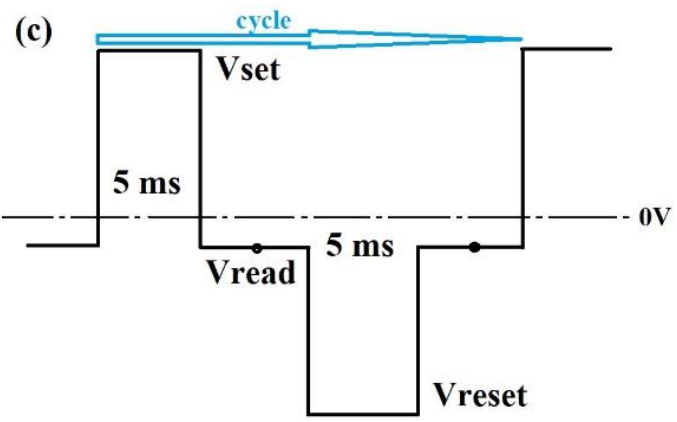

Figure 5. (a) Schematic image of the metal-insulator-semiconductor (MIS) structures. (b) The scheme of the corresponding energy band diagram. (c) The scheme of the measurements of endurance.

The endurance data are shown in Figure 7a-d for MISs grown on the $\mathrm{p}^{+}$-type Si substrate. The endurance measurement scheme is shown in Figure $5 c$. The various $V_{\text {set }}$ and $V_{\text {reset }}$ pulse values were applied to the MIS structures (the values are shown in Figure 7a-d) with a $5 \mathrm{~ms}$ pulse duration. $\mathrm{V}_{\text {read }}$ was always $-1 \mathrm{~V}$. One can see some degradation of the memory window for all MIS structures, mainly caused by a decrease in the ON current (Figure 7). Note that in almost all MIS structures, in addition to the HRS and LRS, the IRS was observed. The IRSs were not clearly distinguishable only in the annealed ITO/GeO[SiO]/ $\mathrm{p}^{+}-\mathrm{Si}(001)$ structure (Figure $7 \mathrm{~d}$ ). The existence of IRSs can be of significant importance for the simulation of neuromorphic devices. The study of the effect of the pulse duration and amplitude on the switching processes (study of the so-called preliminary-spike-enhanced plasticity [19]) is the outlook for future experiments. 

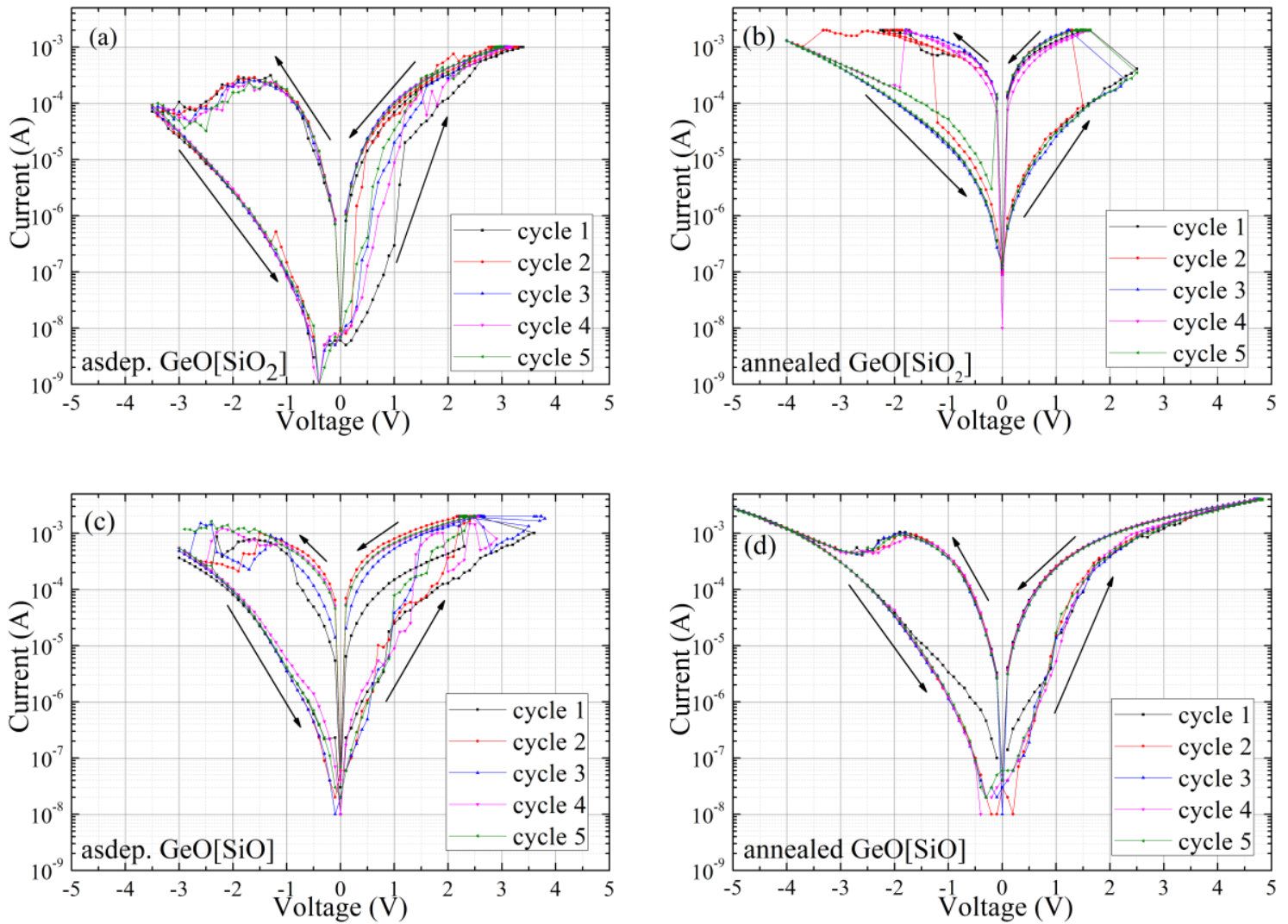

Figure 6. Current-voltage (I-V) characteristics of the MIS structures. (a) As-deposited ITO/GeO $\left[\mathrm{SiO}_{2}\right] / \mathrm{p}^{+}$ -Si (001) heterojunction; (b) Annealed ITO/GeO $\left[\mathrm{SiO}_{2} \mathrm{l} / \mathrm{p}^{+}-\mathrm{Si}\right.$ (001) heterojunction; (c) As-deposited ITO/GeO[SiO] $/ \mathrm{p}^{+}-\mathrm{Si}(001)$ heterojunction; and (d) annealed ITO/GeO[SiO] $/ \mathrm{p}^{+}-\mathrm{Si}(001)$ heterojunction.

Attempts were made to estimate the energy needed to switch on and off the MIS structures and to normalize it to the contact area. It took a $5 \mathrm{~ms}$ long pulse of 4-6 V of voltage, with a maximal current up to $4 \mathrm{~mA}$. The contact area was $0.5 \mathrm{~mm}^{2}$. It can be easily calculated that the energy density value was about $200 \mathrm{~J} / \mathrm{m}^{2}$. If we assume that, in the future ReRAM matrix, the area of the element is $25 \times 25 \mathrm{~nm}$, then the switching energy will be as small as $\sim 100 \mathrm{fJ}$. It should be noted that these estimates were made without considering the influence of possible edge effects. However, it should be noted that the present structure was not optimized and the thickness of the dielectric was too large, while in a real application it should be to the order of $10 \mathrm{~nm}$. Moreover, the switching pulse duration should be a few orders of magnitude smaller. Then, we can hope that the energy required for switching of one element (bit) will be less than $1 \mathrm{fJ}$, which is satisfactory for a memory element.

The contact-limited and volume-limited models were used in order to study the charge transport mechanism of the as-deposited films in an HRS and an LRS like in [18]. It should be remembered that local variations in the chemical composition of the layers of solid germanosilicate alloys led to local variations in the bandgap value (Figure 5b). Moreover, the local bandgap fluctuations led to the local electron potential fluctuations. The charge transport in a non-periodic fluctuating potential can be described according to the Shklovskii-Efros (S-E) percolation model [50]. This model assumes that excited electrons-that is, with an energy higher than the percolation energy level $W$-are delocalized and transfer the charges. In accordance with Equation (5), the $j$ and $F$ characteristics are exponentially dependent:

$$
j=j_{0} \exp \left(-\frac{W-\left(C e F a V_{0}^{\gamma}\right)^{\frac{1}{1+\gamma}}}{k T}\right)
$$


where $j$ is the current density, $F$ is the electric field intensity, $j_{0}$ is the pre-exponential factor, $W$ is the percolation energy, $a$ is the spatial scale of fluctuations, $V_{0}$ is the amplitude of the energy fluctuation, $C \approx 0,25$ is a numerical constant, and $\gamma=0.9$ is a critical index. The percolation energy $W$ and the pre-exponential factor $j_{0}$ determine the homogeneous vertical displacement of $j$ (in a logarithmic scale, as in Figure 8). The spatial scale of the fluctuations and the amplitude of the fluctuation of energy $V_{0}$ determined the slope of the experimental data curve seen in Figure 8. As mentioned above, the simulation was carried out only in the enrichment mode for an Si substrate in order to disregard the contribution of the space charge region in the Si substrate.
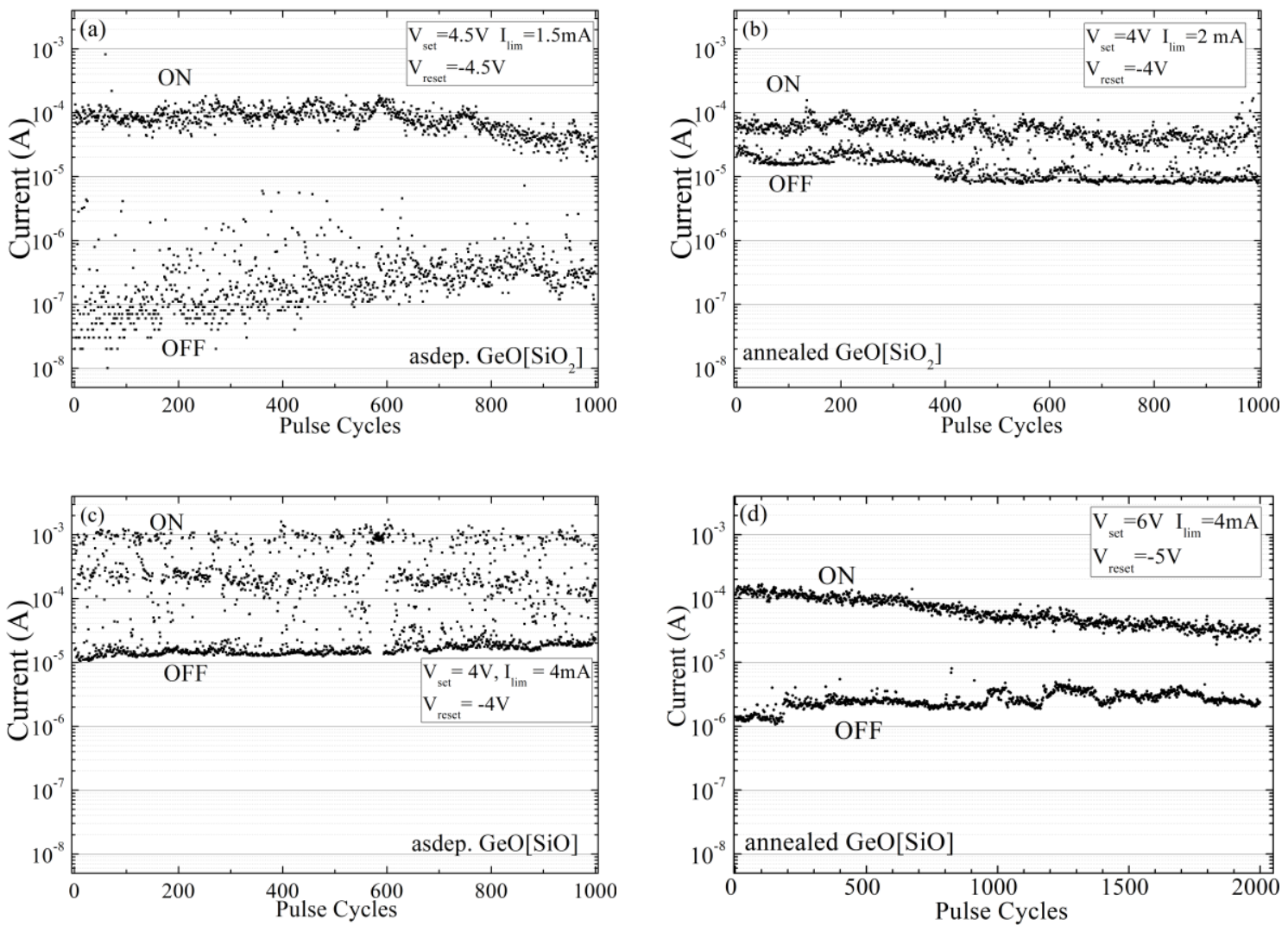

Figure 7. The endurance characteristics of the MIS structures. (a) As-deposited ITO/GeO $\left[\mathrm{SiO}_{2}\right] / \mathrm{p}^{+}-\mathrm{Si}$ (001) heterojunction; (b) Annealed ITO/GeO[SiO 2$] / \mathrm{p}^{+}-\mathrm{Si}$ (001) heterojunction; (c) As-deposited $\mathrm{ITO} / \mathrm{GeO}[\mathrm{SiO}] / \mathrm{p}^{+}-\mathrm{Si}(001)$ heterojunction; and (d) annealed ITO/GeO[SiO $] / \mathrm{p}^{+}-\mathrm{Si}(001)$ heterojunction.

The comparison of the experimental results with the S-E percolation model (for the $\mathrm{GeO}\left[\mathrm{SiO}_{2}\right]$ film on the $\mathrm{n}^{+}$and $\mathrm{p}^{+}$-type substrates) was made earlier [18]. The charge transport in the as-deposited $\mathrm{GeO}[\mathrm{SiO}]$ film on the $\mathrm{n}^{+}$-type substrate was well described by the S-E model, as seen in Figure 8a, although slight deviations by the experimental data in the $\mathrm{GeO}[\mathrm{SiO}]$ film on the $\mathrm{n}^{+}$-type substrate from the S-E percolation model curve can be seen for low electric fields. The fitting parameters of the S-E model for $\mathrm{GeO}[\mathrm{SiO}]$ were the following: $j_{0}=5.1 \times 10^{21} \mathrm{~A} / \mathrm{cm}^{2}, W=1.5 \mathrm{eV}, V_{0}=1.8 \mathrm{eV}$, and $a=2.8 \mathrm{~nm}$. From the change in the $V_{0} \times a$ value, it became possible to suggest that the composition of the $\mathrm{GeO}$ [SiO] film differed from the $\mathrm{GeO}\left[\mathrm{SiO}_{2}\right]$ film [18]. A considerably fine approximation of the experimental data for the $\mathrm{GeO}[\mathrm{SiO}]$ film on the $\mathrm{p}^{+}$-type $\mathrm{Si}$ substrate by the S-E percolation model can be seen in Figure 8b. The fitting parameters of the $\mathrm{S}-\mathrm{E}$ model for $\mathrm{GeO}[\mathrm{SiO}]$ in an HRS were the following: $j_{0}=7.4 \times 10^{21} \mathrm{~A} / \mathrm{cm}^{2}, W_{H R S}=1.64 \mathrm{eV}, V_{0}=2.8 \mathrm{eV}$, and $a=5 \mathrm{~nm}$. Meanwhile, the fitting parameters for $\mathrm{GeO}[\mathrm{SiO}]$ in an LRS were as follows: $j_{0}=7.4 \times 10^{21} \mathrm{~A} / \mathrm{cm}^{2}, W_{L R S}=1.53 \mathrm{eV}, V_{0}=2 \mathrm{eV}$, and $a=3.5 \mathrm{~nm}$. The same $V_{0} \times a$ value in an $\mathrm{LRS}$ for the $\mathrm{GeO}[\mathrm{SiO}]$ and $\mathrm{GeO}\left[\mathrm{SiO}_{2}\right]$ films on a $\mathrm{p}^{+}$-type substrate indicate that the filaments had similar compositions [18]. In addition, the different $V_{0} \times a$ values in an HRS for $\mathrm{GeO}[\mathrm{SiO}]$ and $\mathrm{GeO}\left[\mathrm{SiO}_{2}\right]$ correspond to the difference in their compositions [18]. 
(a)

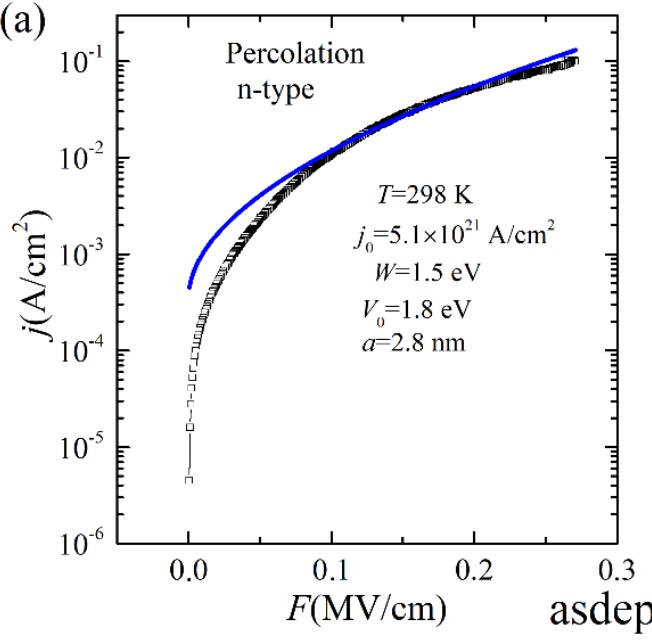

(b)

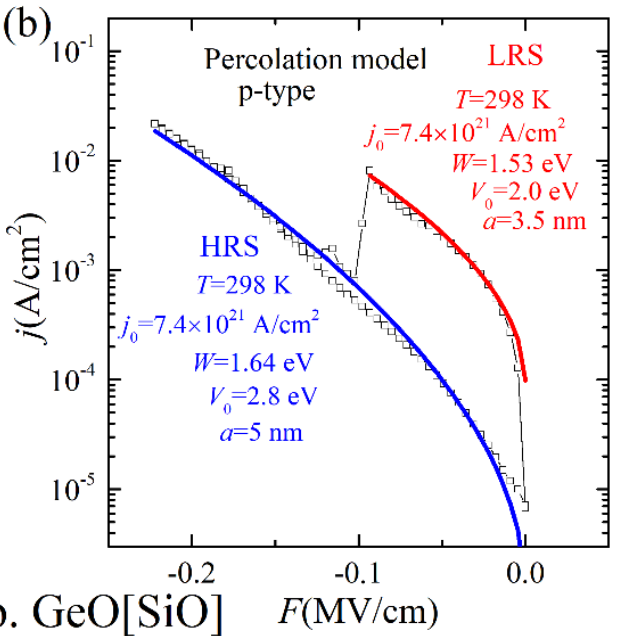

Figure 8. Experimental I-V characteristics of the high resistance state (HRS) and low resistance state (LRS) in as-deposited $\mathrm{GeO}[\mathrm{SiO}]$ films and simulations (colored lines) with the Shklovskii-Efros (S-E) percolation model (a) on the $\mathrm{n}^{+}$-type $\mathrm{Si}$ substrate and (b) on the $\mathrm{p}^{+}$-type $\mathrm{Si}$ substrate.

The standard room temperature was used for modeling in both the HRS and LRS cases. Since we used a slow voltage sweep to measure the I-V characteristics, the effects of the local temperature shifts in the percolation channels were not considered in the present study. Therefore, the real average temperature of the entirety of the structures was close to room temperature.

We highlight that switching to an LRS in our system took place due to the formation of the filaments of oxygen vacancies (like in [15]) or oxygen multi-vacancies. The schematics of the proposed mechanism of the formation and rupture of these conducting filaments between electrodes via a-Ge nanoclusters are demonstrated in Figure 9. The absence of the need for forming has been demonstrated in the experiments (e.g., by applying a primary high positive voltage to the upper electrode). The bottom electrode, made of $\mathrm{p}^{+}-\mathrm{Si}$, was grounded. No filaments (center image) could be observed in the absence of an external electric field. The essence of the proposed model lies in the organizing action of a-Ge particles with a size of $\sim 3 \mathrm{~nm}$ inside a $64-85 \mathrm{~nm}$ thin layer of germanosilicate glass, which builds a conducting channel of oxygen vacancies even at a low voltage setting (one to the order of $+2 \mathrm{~V}$ ), leading to the formation of a conducting filament (shown in the right image). The absence of the forming stage reduced the time and the total energy consumption necessary for reaching the operating state of the memory element. At voltages of about $-3 \mathrm{~V}$, a reset mode was observed (shown in the left image), after which the write-erase cycle of information in the memristor could be effectively repeated many times. The model is consistent with our recent experimental observations (Figures 5 and 6) and with earlier models for similar systems. The novelty of the present model is based on taking into account the organizing influence of a-Ge nanoclusters. The sink for oxygen ions during electromigration can not only be the bottom Si electrode, but also the Ge nanoclusters.

However, it should be noted that additional explanation of the resistive switching can be in the charging and discharging of the deep traps in the $\mathrm{GeSi}_{x} \mathrm{O}_{y}$ films. Charged traps, with their extra potential, change the flow conditions for electrons and holes in the S-E percolation model [51]. Such deep traps could be a-Ge nanoclusters. The distance between them exceeds the value favorable for sub-barrier tunneling (a few $\mathrm{nm}$, as one can see in Figure 2). The LRS state can be achieved only if conducting filaments are formed between a-Ge clusters, as shown in Figure 9. Thus, the model of filament formation, in our opinion, is the main explanation for resistive switching. As a further outlook, the elucidation of this issue should be done. Other further directions of this research will be related to optimization of the structure of the films in order to increase the ON/OFF ratio in resistance switching and to improvement of the endurance. 


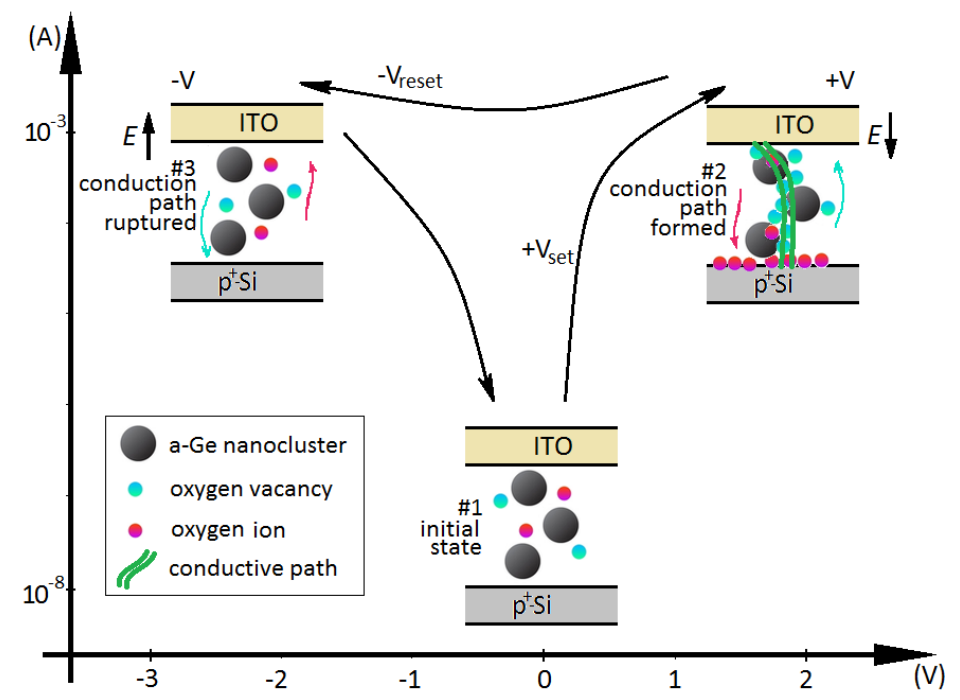

Figure 9. Schematics of the formation (right) and rupture (left) of a conducting a-Ge-based filament in the $\mathrm{GeSi}_{\mathrm{x}} \mathrm{O}_{\mathrm{y}}$ structure under the external electric field, taking into account the movement of oxygen ions and oxygen vacancies.

\section{Conclusions}

Stable resistive switching was observed in MIS memristor structures based on non-stoichiometric germanosilicate $\left(\mathrm{GeSi}_{\mathrm{x}} \mathrm{O}_{\mathrm{y}}\right)$ films with and without amorphous Ge nanoclusters. The prevailing mechanism of the observed resistive switching is the formation and rupture of conducting filaments. The formation and rupture of the filaments is caused by the electromigration of oxygen ions and oxygen vacancies. The endurance studies showed that some degradation of the memory window occurred for all structures, and it was mainly caused by a decrease of the ON current. In almost all MIS structures, intermediate resistance states (IRSs) were observed, in addition to the HRS and LRS. The studied memristors can be used for the simulation of prospective neuromorphic devices.

Supplementary Materials: The following are available online at http://www.mdpi.com/2079-9292/9/12/2103/s1. Figure S1: The 2D AFM topography images of the $\mathrm{GeO}\left[\mathrm{SiO}_{2}\right]$ samples: (a) as-deposited; (b) annealed; Figure S2: Power spectral density (PSD) of roughness measured for fast scan axis direction X shows small values of object sizes $\left(X\right.$-axis, $\left.\mathrm{nm}^{3}\right)$ and amount of objects $\left(Y\right.$-axis, $\left.\mu \mathrm{m}^{-1}\right)$ for the entire spectral range; Figure S3: Transmittance and reflectance curves for $\mathrm{GeO}\left[\mathrm{SiO}_{2}\right]$ and $\mathrm{GeO}[\mathrm{SiO}]$ films on quartz substrates: left image-as-deposited films; right image-annealed films; Figure S4: Exemplary experimental I-V characteristics of the as-deposited $\left.\mathrm{GeO}_{[} \mathrm{SiO}_{2}\right]$; Table S1: Roughness parameters of Si surfaces.

Author Contributions: Conceptualization, V.A.V.; formal analysis, G.N.K., A.A.G., G.K.K., I.P.P., I.A.A. and Z.F.; investigation, V.A.V., G.N.K., A.A.G., G.K.K., I.P.P., I.A.A., Z.F. and M.V.; project administration, P.G.; resources, M.V.; visualization, P.G.; writing—original draft, V.A.V.; writing—review and editing, P.G. All authors have read and agreed to the published version of the manuscript.

Funding: This work was supported by the Ministry of Education and Science of the Russian Federation, grant FSUS-2020-0029, while XPS and I-V curve analysis was done with financial support of the grant 075-15-2020-797 (13.1902.21.0024). The Raman spectroscopy and TEM were done on the equipment of CKP "VTAN" in the ATRC department of NSU.

Acknowledgments: The authors are thankful to Alexandre Bouché for help in growing the samples.

Conflicts of Interest: The authors declare no conflict of interest.

\section{References}

1. Zidan, M.A.; Strachan, J.P.; Lu, W.D. The future of electronics based on memristive systems. Nat. Electron. 2018, 1, 22. [CrossRef]

2. Chua, L.O.; Kang, S.M. Memristive devices and systems. Proc. IEEE 1976, 64, 2. [CrossRef] 
3. Strukov, D.B.; Snider, G.S.; Stewart, D.R.; Stanley Williams, R. The missing memristor found. Nature 2008, 453, 80. [CrossRef] [PubMed]

4. Terai, M.; Sakotsubo, Y.; Kotsuji, S.; Hada, H. Resistance Controllability of $\mathrm{Ta}_{2} \mathrm{O}_{5} / \mathrm{TiO}_{2}$ Stack ReRAM for Low-Voltage and Multilevel Operation. IEEE Electron. Device Lett. 2010, 31, 204. [CrossRef]

5. Yan, K.; Peng, M.; Yu, X.; Cai, X.; Chen, S.; Hu, H.; Chen, B.; Gao, X.; Dong, B.; Zou, D. High-performance perovskite memristor based on methyl ammonium lead halides. J. Mater. Chem. C 2016, 4, 1375. [CrossRef]

6. Battistoni, S.; Erokhin, V.; Iannotta, S. Organic memristive devices for perceptron applications. J. Phys. D Appl. Phys. 2018, 51, 284002. [CrossRef]

7. Romero, F.J.; Toral, A.; Medina-Rull, A.; Moraila-Martinez, C.L.; Morales, D.P.; Ohata, A.; Godoy, A.; Ruiz, F.G.; Rodriguez, N. Resistive Switching in Graphene Oxide. Front. Mater. 2020, 7, 17. [CrossRef]

8. Lee, H.Y.; Chen, P.S.; Wu, T.Y.; Wang, C.C.; Tzeng, P.J.; Lin, C.H.; Chen, F.; Tsai, M.-J. Low power and high speed bipolar switching with a thin reactive Ti buffer layer in robust $\mathrm{HfO}_{2}$ based RRAM. In Proceedings of the IEEE International Electron Devices Meeting, San Francisco, CA, USA, 15-17 December 2008.

9. Wei, Z.; Kanzawa, Y.; Arita, K.; Katoh, Y.; Kawai, K.; Muraoka, S.; Mitani, S.; Fujii, S.; Katayama, K.; Iijima, M.; et al. Highly reliable $\mathrm{TaO}_{\mathrm{x}}$ ReRAM and direct evidence of redox reaction mechanism. In Proceedings of the IEEE International Electron Devices Meeting, San Francisco, CA, USA, 15-17 December 2008.

10. Lee, M.J.; Lee, C.B.; Lee, D.; Lee, S.R.; Chang, M.; Hur, J.H.; Kim, Y.B.; Kim, C.J.; Seo, D.H.; Seo, S.; et al. A fast, high-endurance and scalable non-volatile memory device made from asymmetric $\mathrm{Ta}_{2} \mathrm{O}_{(5-\mathrm{x})} / \mathrm{TaO}_{(2-\mathrm{x})}$ bilayer structures. Nat. Mater. 2011, 10, 625. [CrossRef]

11. Shaposhnikov, A.V.; Perevalov, T.V.; Gritsenko, V.A.; Cheng, C.H.; Chin, A. Mechanism of $\mathrm{GeO}_{2}$ resistive switching based on the multi-phonon assisted tunneling between traps. Appl. Phys. Lett. 2012, 100, 243506. [CrossRef]

12. Yen, T.J.; Chin, A.; Gritsenko, V. High Performance All Nonmetal $\mathrm{SiN}_{\mathrm{x}}$ Resistive Random Access Memory with Strong Process Dependence. Sci. Rep. 2020, 10, 2807. [CrossRef]

13. Zackriya, M.; Kittur, H.M.; Chin, A. A Novel Read Scheme for Large Size One-Resistor Resistive Random Access Memory Array. Sci. Rep. 2017, 7, 42375. [CrossRef] [PubMed]

14. Mehonic, A.; Shluger, A.L.; Gao, D.; Valov, I.; Miranda, E.; Ielmini, D.; Bricalli, A.; Ambrosi, E.; Li, C.; Yang, J.J.; et al. Silicon Oxide $\left(\mathrm{SiO}_{\mathrm{x}}\right)$ : A Promising Material for Resistance Switching? Adv. Mater. 2018, 30, 1801187. [CrossRef] [PubMed]

15. Kawauchi, T.; Kano, S.; Fujii, M. Forming-free resistive switching in solution-processed silicon nanocrystal thin film. J. Appl. Phys. 2018, 124, 085113. [CrossRef]

16. Fan, J.; Kapur, O.; Huang, R.; King, S.W.; de Groot, C.H.; Jiang, L. Back-end-of-line a-SiO $\mathrm{C}_{\mathrm{y}}: \mathrm{H}$ dielectrics for resistive memory. AIP Adv. 2018, 8, 095215. [CrossRef]

17. Yen, T.J.; Gismatulin, A.; Volodin, V.; Gritsenko, V.; Chin, A. All Nonmetal Resistive Random Access Memory. Sci. Rep. 2019, 9, 6144. [CrossRef]

18. Volodin, V.A.; Kamaev, G.N.; Gritsenko, V.A.; Gismatulin, A.A.; Chin, A.; Vergnat, M. Memristor effect in $\mathrm{GeO}\left[\mathrm{SiO}_{2}\right]$ and $\mathrm{GeO}[\mathrm{SiO}]$ solid alloys films. Appl. Phys. Lett. 2019, 114, 233104. [CrossRef]

19. Hwang, H.G.; Woo, J.U.; Lee, T.H.; Park, S.M.; Lee, T.G.; Lee, W.H.; Nahm, S. Synaptic plasticity and preliminary-spike-enhanced plasticity in a CMOS-compatible $\mathrm{Ta}_{2} \mathrm{O}_{5}$ memristor. Mater. Des. 2020, 187, 108400. [CrossRef]

20. Wang, R.; Shi, T.; Zhang, X.; Wang, W.; Wei, J.; Lu, J.; Zhao, X.; Wu, Z.; Cao, R.; Long, S.; et al. Bipolar analog Memristors as artificial synapses for neuromorphic computing. Materials 2018, 11, 2102. [CrossRef]

21. Ardyanian, M.; Rinnert, H.; Devaux, X.; Vergnat, M. Structure and photoluminescence properties of evaporated GeOx thin films. Appl. Phys. Lett. 2006, 89, 011902. [CrossRef]

22. Marin, D.V.; Volodin, V.A.; Gorokhov, E.B.; Shcheglov, D.V.; Latyshev, A.V.; Vergnat, M.; Koch, J.; Chichkov, B.N. Modification of germanium nanoclusters in $\mathrm{GeO}_{\mathrm{x}}$ films during isochronous furnace and pulse laser annealing. Appl. Phys. Lett. 2010, 36, 439.

23. Moulder, J.F.; Stickle, W.F.; Sobol, P.E.; Bomben, K.D. Handbook of X-ray Photoelectron Spectroscopy; Chastain, J., Ed.; Perkin-Elmer: Eden Prairie, MN, USA, 1992; p. 190.

24. Gritsenko, V.A.; Kruchinin, V.N.; Prosvirin, I.P.; Novikov, Y.N.; Chin, A.; Volodin, V.A. Atomic and Electronic Structures of a-SiN $\mathrm{x}:$ H. J. Exp. Theor. 2019, 129, 924. [CrossRef]

25. Zhigunov, D.M.; Kamaev, G.N.; Kashkarov, P.K.; Volodin, V.A. On Raman scattering cross section ratio of crystalline and microcrystalline to amorphous silicon. Appl. Phys. Lett. 2018, 113, 023101. [CrossRef] 
26. Fan, Z.; Kochubey, S.A.; Stoffel, M.; Rinnert, H.; Vergnat, M.; Volodin, V.A. On the Formation of Amorphous Ge Nanoclusters and Ge Nanocrystals in $\mathrm{GeSi}_{\mathrm{x}} \mathrm{O}_{\mathrm{y}}$ Films on Quartz Substrates by Furnace and Pulsed Laser Annealing. Semiconductors 2020, 54, 322.

27. Scofield, J.H. Hartree-Slater subshell photoionization cross-sections at 1254 and 1487 eV. J. Electron. Spectros. Relat. Phenom. 1976, 8, 129. [CrossRef]

28. Kalimuthu, V.; Kumar, P.; Kumar, M.; Rath, S. Growth mechanism and optical properties of Ge nanocrystals embedded in a $\mathrm{GeO}_{\mathrm{x}}$ matrix. Appl. Phys. A 2018, 124, 712. [CrossRef]

29. Tabet, N.; Faiz, M.; Hamdan, N.M.; Hussain, Z. High resolution XPS study of oxide layers grown on Ge substrates. Surf. Sci. 2003, 523, 68. [CrossRef]

30. Xpspeak Software Web Site. Available online: http://xpspeak.software.informer.com/4.1/ (accessed on 9 November 2020).

31. Gambaryan, M.P.; Krivyakin, G.K.; Cherkova, S.G.; Stoffel, M.; Rinnert, H.; Vergnat, M.; Volodin, V.A. Quantum Size Effects in Germanium Nanocrystals and Amorphous Nanoclusters in $\mathrm{GeSi}_{\mathrm{x}} \mathrm{O}_{\mathrm{y}}$ Films. Phys. Solid State 2020, 62, 492. [CrossRef]

32. Kolobov, A.V. Raman scattering from Ge nanostructures grown on Si substrates: Power and limitations. J. Appl. Phys. 2000, 87, 2926. [CrossRef]

33. Cerdeira, F.; Fjeldly, T.A.; Cardona, M. Raman study of the interaction between localized vibrations and electronic excitations in boron-doped silicon. Phys. Rev. B 1974, 9, 4344. [CrossRef]

34. Wihl, M.; Cardona, M.; Tauc, J. Raman scattering in amorphous Ge and III-V compounds. J. Non-Cryst. Solids 1972, 8-10, 172-178. [CrossRef]

35. Volodin, V.A.; Kamaev, G.N.; Vergnat, M. Negative and Positive Photoconductivity and Memristor Effect in Alloyed GeO[SiO] Films Containing Ge Nanoclusters. Phys. Stat. Sol. (RRL) 2020, 14, 2000165. [CrossRef]

36. Gorokhov, E.B.; Volodin, V.A.; Marin, D.V.; Orekhov, D.A.; Cherkov, A.G.; Gutakovskii, A.K.; Shwets, V.A.; Borisov, A.G.; Efremov, M.D. Effect of quantum confinement on optical properties of Ge nanocrystals in $\mathrm{GeO}_{2}$ films. Semiconductors 2005, 39, 1168. [CrossRef]

37. Lucovsky, G.; Yang, J.; Chao, S.S.; Tyler, J.E.; Czubatyj, W. Oxygen-bonding environments in glow-discharge-deposited amorphous silicon-hydrogen alloy films. Phys. Rev. B 1983, 28, 3225. [CrossRef]

38. Pai, P.G.; Chao, S.S.; Takagi, Y.; Lucovsky, G. Infrared spectroscopic study of $\mathrm{SiO}_{\mathrm{x}}$ films produced by plasma enhanced chemical vapor deposition. J. Vac. Sci. Technol. A 1986, 4, 689. [CrossRef]

39. Cherkova, S.G.; Volodin, V.A.; Skuratov, V.A.; Stoffel, M.; Rinnert, H.; Vergnat, M. Infrared photoluminescence from $\mathrm{GeO}\left[\mathrm{SiO}_{2}\right]$ and $\mathrm{GeO}[\mathrm{SiO}]$ solid alloy layers irradiated with swift heavy Xe ions. J. Lumin. 2020, 223, 117238. [CrossRef]

40. Seck, M.; Devine, R.A.B.; Hernandez, C.; Campidelli, Y.; Dupuy, J.C. Study of Ge bonding and distribution in plasma oxides of $\mathrm{Si}_{1-\mathrm{x}} \mathrm{Ge}_{\mathrm{x}}$ alloys. Appl. Phys. Lett. 1998, 72, 2748. [CrossRef]

41. Shabalov, A.L.; Feldman, M.S. Optical properties of thin $\mathrm{GeO}_{\mathrm{x}}$ films. Phys. Status Solidi A 1984, 83, K11. [CrossRef]

42. Jishiashvili, D.A.; Kutelia, E.R. Infrared Spectroscopic Study of $\mathrm{GeO}_{\mathrm{x}}$ Films. Phys. Status Solidi B 1987, 143, K147. [CrossRef]

43. Perevalov, T.V.; Volodin, V.A.; Kamaev, G.N.; Krivyakin, G.K.; Gritsenko, V.A.; Prosvirin, I.P. Electronic structure and nanoscale potential fluctuations in strongly nonstoichiometric PECVD $\mathrm{SiO}_{\mathrm{x}}$. J. Non-Cryst. Solids 2020, 529, 119796. [CrossRef]

44. Tompkins, H.G.; Irene, E.A. Handbook of Ellipsometry; William Andrew Pub: Norwich, NY, USA, 2005.

45. Marin, D.V.; Gorokhov, E.B.; Borisov, A.G.; Volodin, V.A. Ellipsometry of $\mathrm{GeO}_{2}$ films with Ge nanoclusters: Influence of the quantum-size effect on refractive index. Opt. Spectrosc. 2009, 106, 436. [CrossRef]

46. Volodin, V.A.; Gambaryan, M.P.; Cherkov, A.G.; Stoffel, M.; Rinnert, H.; Vergnat, M. Structure and infrared photoluminescence of GeSi nanocrystals formed by high temperature annealing of $\mathrm{GeO}_{\mathbf{x}} / \mathrm{SiO}_{2}$ multilayers. Mater. Res. Express 2016, 3, 085019. [CrossRef]

47. Gritsenko, V.A.; Volodin, V.A.; Perevalov, T.V.; Kruchinin, V.N.; Gerasimova, A.K.; Aliev, V.S.; Prosvirin, I.P. Nanoscale potential fluctuations in nonstoichiometrics tantalum oxide. Nanotechnology 2018, $29,425202$. [CrossRef]

48. Broqvist, P.; Binder, J.F.; Pasquarello, A. Band offsets at the $\mathrm{Ge} / \mathrm{GeO}_{2}$ interface through hybrid density functionals. Appl. Phys. Lett. 2009, 94, 141911. [CrossRef] 
49. Tikhov, S.V.; Gorshkov, O.N.; Antonov, I.N.; Kasatkin, A.P.; Korolev, D.S.; Belov, A.I.; Mikhaylov, A.N.; Tetel'baum, D.I. Change of immitance during electroforming and resistive switching in the metal-insulator-metal memristive structures based on $\mathrm{SiO}_{x}$. Tech. Phys. 2016, 61, 745-749. [CrossRef]

50. Shklovskii, B.I.; Efros, A.L. Percolation theory and conductivity of strongly inhomogeneous media. Sov. Phys. Usp. 1976, 18, 846-862.

51. Efremov, M.D.; Kamaev, G.N.; Volodin, V.A.; Arzhannikova, S.A.; Kachurin, G.A.; Cherkova, S.G.; Kretinin, A.V.; Malyutina-Bronskaya, V.V.; Marin, D.V. Coulomb blockade of the conductivity of $\mathrm{SiO}_{\mathrm{x}}$ films due to one-electron charging of a silicon quantum dot in a chain of electronic states. Semiconductors 2005, 39, 910. [CrossRef]

Publisher's Note: MDPI stays neutral with regard to jurisdictional claims in published maps and institutional affiliations.

(C) 2020 by the authors. Licensee MDPI, Basel, Switzerland. This article is an open access article distributed under the terms and conditions of the Creative Commons Attribution (CC BY) license (http://creativecommons.org/licenses/by/4.0/). 